\title{
Organic Fertilizers and Soil Conditioner Recover Chemical Fertilizer-Induced Changes in Soil Bacterial Community Diversity in Wine Grape Rhizosphere Soil
}

\author{
Rui Wang ${ }^{1,2}$, Ting Hou ${ }^{1}$, Quan Sun ${ }^{1}$, Lidong $\mathrm{Ji}^{3}$, Jinyin Lei ${ }^{3}$, Junxiang Zhang* \\ ${ }^{1}$ School of Agricultural, Ningxia University, Yinchuan, Ningxia 750021, P.R. China \\ ${ }^{2}$ Ningxia Grape and Wine Research Institute, Yinchuan, Ningxia 750021, P.R. China \\ ${ }^{3}$ Institute of Agricultural Resources and Environment, Ningxia Academy of Agriculture and Forestry Science, \\ Yinchuan, Ningxia 750001, P.R. China
}

Received: 31 January 2020

Accepted: 7 August 2020

\begin{abstract}
Different fertilization strategies can affect the quality of grapes, which in turn affect the taste of wine. This study aimed to investigate the effects of different fertilization treatments on soil fertility and wine grape berry quality, as well as the relationship of soil bacterial diversity and fertilization. Six-year-old Vitis vinifera L. cv. Cabernet Sauvignon plants were randomly planted in 25 test plots with five fertilization treatments: no fertilization, chemical fertilizer, organic fertilizer, combined chemical and organic fertilizers, and combined chemical, organic fertilizers and soil conditioner. Chemical properties of soil and grape berry quality indicators were detected. The soil bacterial diversity was analyzed using Illumina sequencing. Chemical fertilizer increased the available $\mathrm{P}$ and $\mathrm{K}$ contents and total $\mathrm{N}$ content, while the addition of organic fertilizers and/or soil conditioner increased their contents and the organic matter. The favorable effects of the application of organic fertilizers and soil conditioners on soil fertility and grape quality might be associated with the abundance changes of soil bacteria, including Gemmatimonadetes and Actinobacteria phyla as well as Rubrobacter and Steroidobacter genera. We concluded that the organic fertilizers and soil conditioners could enhance soil fertility and improve wine grape quality, which might be associated with the changes of soil bacteria of Gemmatimonadetes, Actinobacteria, Rubrobacter and Steroidobacte.
\end{abstract}

Keywords: soil bacterial diversity, organic fertilizers, soil conditioner, wine grape

*e-mail: nxzhangjunxiang@126.com 


\section{Highlights}

1. Organic fertilizers and soil conditioners enhanced soil fertility.

2. Organic fertilizers and soil conditioners improved wine grape berry quality.

3. The bacterial diversity was decreased chemical fertilizers but increased by organic fertilizer, especially in Gemmatimonadetes and Actinobacteria.

4. Rubrobacter genus was decreased by chemical fertilizers and recovered by organic fertilizers.

\section{Introduction}

Wine grape (Vitis vinifera, V. vinifera) is an important fruit crop with high economic value in the wine business [1]. It has been proved that long-term drinking of wine is beneficial to the prevention of cardiovascular diseases and chronic diseases, because of the specific trace elements, amino acids, organic acids, etc. in wine [2]. The taste and quality of the wine mainly depend on the quality of the wine grape, followed by the winemaking process [3]. The content and balance of soluble solid, titratable acid, tannin, total phenols, and anthocyanin in wine grapes determine the quality of wine grape berry [3]. Thus, considering the beneficial effect of wine on human health, searching for strategies to improve the quality and yield of wine grape berry is necessary.

The quality and yield of wine grape are directly influenced by soil type, soil structure, soil thickness, soil fertility, soil temperature and moisture [4]. Under the unmodifiable climatic condition and soil type, the improvement of soil fertility by applying fertilizers is predominant strategy for the yield and quality of crops [5-7]. Soil fertility is mainly improved by various fertilizers such as chemical, organic and microbial fertilizers as well as soil conditioners [6]. Overwhelming evidence has demonstrated that long-term application of chemical fertilizers induce several adverse effects on soil, including the continuously reduced organic matter content, the imbalanced nutrient content, and reduced sustainable production capacity $[8,9]$. Fortunately, the application of organic fertilizers and soil conditioners significantly increases the yield and quality of crops, as well as improves soil organic matter content and soil fertility $[9,10]$. Therefore, reasonable fertilization with organic fertilizers and soil conditioners is recommended to improve soil fertility.

In agroecosystems, soil bacterial diversity is of crucial importance in the yield and quality of crops [11-13]. It has been widely studied that soil bacterial community diversity can be influenced by various fertilizers [14]. Plants depend on soil microorganisms for recycling nutrients, while soil microbes rely on plants for their energy requirements. The soil microbial communities respond strongly to the plantation, and show a significant correlation of soil microbial community compositions with soil physicochemical parameters [15]. Under stable climatic conditions, soil nutrients are the key factors affecting fruit quality. Therefore, ameliorating soil nutrients is among the common methods used to improve fruit quality. However, the influence of chemical fertilizers, organic fertilizers and soil conditioners in soil bacterial diversity of wine grape is barely reported. In this study, the effects of different fertilization treatments on soil chemical properties and wine grape $(V$. vinifera $\mathrm{L}$. cv. Cabernet sauvignon) berry quality were evaluated. Furthermore, soil bacterial community diversity was analyzed using Illumina high-throughput sequencing technology, and the relationship of soil bacterial diversity and different fertilization treatments was also discussed. This study would provide us with more information on managing the fertilization of grape in view of soil bacteria for improving the grape quality.

\section{Experimental Procedures}

\section{Experimental Site}

The experimental site is located in the wine grape planting base of Lilan Winery, at the eastern foothills of Helan Mountain, Minning town, Yongning county, Yinchuan city, Ningxia province, China (latitude $38^{\circ} 16^{\prime} 38^{\prime \prime} \mathrm{N}$, longitude $105^{\circ} 58^{\prime} 20^{\prime \prime} \mathrm{E}$, above sea level $1129 \mathrm{~m})$. The site is temperate continental arid climate with the annual sunshine rate of over $65 \%$, the total solar radiation of $6100 \mathrm{MJ} / \mathrm{m}^{2}$, the annual average temperature of $8.8^{\circ} \mathrm{C}$, accumulated temperature of 3289 ${ }^{\circ} \mathrm{C}$, annual average rainfall of $200 \mathrm{~mm}$, annual average evaporation of $1580 \mathrm{~mm}$, and frost-free period of 176 d. The terrain of the experimental site is gentle, with a slope of about $1 \%$ on the ground and an average altitude of $1060 \mathrm{~m}$. The soil type of the vineyard is sierozem with loamy sand. The baseline chemical parameters of soil at this site are shown in (Table 1).

\section{Experimental Design and Sampling}

Six-year-old $V$. vinifera L. cv. Cabernet Sauvignon was used as the experimental variety in this study. All the plants were planted in the north-south orientation with the planting density of $0.6 \mathrm{~m} \times 3.5 \mathrm{~m}$ (plant distance $\times$ row spacing). Totally, 25 test plots were set with 60 grape plants in each plot and randomly divided into five groups using a single factor randomized block design. Plots in the five groups were fertilized according to following tactics: CK (no fertilization), $\mathrm{F}_{\mathrm{CF}}(100 \%$ chemical fertilizer; the composition and the application rate: pure $\mathrm{N} 363 \mathrm{~kg} / \mathrm{hm}^{2}, \mathrm{P}_{2} \mathrm{O}_{5} 177 \mathrm{~kg} / \mathrm{hm}^{2}$, and $\left.\mathrm{K}_{2} \mathrm{O} 330 \mathrm{~kg} / \mathrm{hm}^{2}\right), \mathrm{F}_{\mathrm{OF}}(100 \%$ organic fertilizer; the application rate: $\left.9 \mathrm{t} / \mathrm{hm}^{2}\right), \mathrm{F}_{\mathrm{OC}}(50 \%$ organic fertilizer + $50 \%$ chemical fertilizer), $\mathrm{F}_{\mathrm{OC} / 4}(25 \%$ organic fertilizer $+25 \%$ chemical fertilizer $+50 \%$ soil conditioner; the application rate of soil conditioner: $3 \mathrm{t} / \mathrm{hm}^{2}$ ). The 
Table 1. The baseline chemical parameters of soil at the experimental site.

\begin{tabular}{|c|c|c|c|}
\hline \multirow{2}{*}{ Parameters } & \multicolumn{3}{|c|}{ Soil depth $(\mathrm{cm})$} \\
\cline { 2 - 4 } & $0-20$ & $20-40$ & $40-60$ \\
\hline $\mathrm{pH}$ & 8.82 & 8.87 & 8.90 \\
\hline Organic matter $(\mathrm{g} / \mathrm{kg})$ & 6.26 & 5.78 & 4.82 \\
\hline Available N $(\mathrm{mg} / \mathrm{kg})$ & 24.03. & 21.27 & 13.93 \\
\hline Available P $(\mathrm{mg} / \mathrm{kg})$ & 6.73 & 4.46 & 2.03 \\
\hline Available $\mathrm{K}(\mathrm{mg} / \mathrm{kg})$ & 223.33 & 183.84 & 117.62 \\
\hline Total N $(\mathrm{g} / \mathrm{kg})$ & 0.48 & 0.44 & 0.22 \\
\hline Total P $(\mathrm{g} / \mathrm{kg})$ & 0.28 & 0.22 & 0.17 \\
\hline
\end{tabular}

organic fertilizer is sheep manure with organic matter $\geq 45 \%$ and $\mathrm{N}+\mathrm{P}_{2} \mathrm{O}_{5}+\mathrm{K}_{2} \mathrm{O} \geq 5 \%$ ); and soil conditioner is consisted of organic matter $\geq 25 \%, \mathrm{Ca} \geq 20 \%, \mathrm{~N}+$ $\mathrm{P}_{2} \mathrm{O}_{5}+\mathrm{K}_{2} \mathrm{O} \geq 5 \%, \mathrm{Zn}+\mathrm{Fe}+\mathrm{Cu}+\mathrm{B}+\mathrm{Mn} \geq 1.5 \%(\mathrm{pH}$ 6.5-7.5). All fertilizers were applied once in the initial stage (May 2018). The treatment was performed in 5 individuals (each is a repeat) with regular irrigation of $3000 \mathrm{~m}^{3} / \mathrm{hm}^{2}$ per year. Soil samples in root rhizosphere were collected from each plot at the mature stage of wine grape on July 2018, and then transported to laboratory using the sterilized plastic bag for $16 \mathrm{~s}$ sequence experiment. Bulk soil samples at different layers (0-20 cm, 20-40 cm and 40-60 cm depth) were also sampled for chemical properties detection. All the soil samples were stored under -80 conditions until use.

\section{Detection of Chemical Properties of Soil}

The chemical properties of soil samples $(0-20 \mathrm{~cm}$, $20-40 \mathrm{~cm}$ and 40-60 $\mathrm{cm}$ depth), including organic matter, available $\mathrm{N}$, available $\mathrm{P}$, total $\mathrm{N}$ and total $\mathrm{P}$, were detected in this study. Five soil samples were collected from each experimental plot. Soil samples were dried, ground into power and filtered before the detection. All the determinations were performed according to the methods reported by Bao in 2000 [16]. Briefly, the organic matter was determined using potassium bichromate titrimetric method. The available $\mathrm{N}, \mathrm{P}$ and $\mathrm{K}$ contents were determined using alkaline hydrolysis diffusion method, $0.5 \mathrm{~mol} / \mathrm{L} \mathrm{NaHCO}_{3}$ extraction-colorimetric method, and $\mathrm{CH}_{3} \mathrm{COONH}_{4}$ extraction-flame photometric methods, respectively. Total $\mathrm{N}$ and $\mathrm{P}$ contents were determined using sulfuric acid elimination-Kjeldahl determination methods and Vanadium molybdate yellow colorimetry, respectively.

\section{Determination of the Quality of Wine Grapes}

The ripening grape berries from the same location of grapevines were harvested for the determination of grape berries quality parameters, including soluble solid, titratable acid, tannin, total phenols, and anthocyanin. All the quality indexes were determined according to the methods reported by $\mathrm{Li}$ et al [17]: soluble solids was determined by handheld digital refractometer; titratable acid was determined by $\mathrm{NaOH}$ titration method (calculated as tartaric acid); the tannin content was determined using Folin-Denis method; the content of the total phenolic was determined by the Folin-Ciocalteu method; and the anthocyanin content was determined by $\mathrm{pH}$ differential spectrophotometry. Each examination was repeated for at least 3 times.

\section{DNA Extraction, Library Preparation and Sequencing}

Soil DNA was extracted from $250 \mathrm{mg}$ soil per sample using MoBio Power Soil DNA isolation kit (MoBio laboratories, Carlsbad, CA, USA) according to the manufacturer's instructions. The concentration and purity of the extracted DNA were detected using NanoDrop ND-1000 spectrophotometer (NanoDrop Technologies, Wilmington, DE, USA), and the integrity of DNA samples was detected by $1 \%$ agarose gel electrophoresis. The $16 \mathrm{~S}$ rRNA amplicons covering variable region $\mathrm{V} 4$ were amplified used specific primer (16S V4: 515F-806R) with the barcode [18]. PCR reaction was conducted with TransGen AP22102: TransStart Fastpfu DNA Polymerase (TransGen Biotech, Beijing, China). The PCR products were quantified with electrophoresis on $2 \%$ agarose gel and then purified with Qiagen Gel Extraction Kit (Qiagen, Hilden, Germany). Sequencing libraries were constructed using TruSeq ${ }^{\circledR}$ DNA PCR-Free Sample Preparation Kit (Illumina, San Diego, CA, USA), and the quality of libraries was evaluated on the Qubit@2.0 Fluorometer (Thermo Scientific, MA, USA) and Agilent Bioanalyzer 2100 system. Following that, the libraries were sequenced on the IlluminaHiSeq2500 platform and 250 bp paired-end reads were produced.

\section{Data Preprocessing}

The paired-end reads were assigned to the samples according to their unique barcode and were truncated by cutting off the barcode and primer sequence. The sequences with average base quality $\geq Q 20$, length $\geq 200$ bp and without ambiguous base were screened out and then merged using FLASH (v1.2.7, http://ccb.jhu.edu/software/FLASH/) according to the overlapping bases. The obtained sequences were further performed quality filtering using Quantitative Insights Into Microbial Ecology (QIIME v1.8.0, http:// qiime.org/). Additionally, the chimera sequences were also removed using USEARCH (v5.2.236, http://www. drive5.com/usearch/)[19].

\section{Bioinformatics Analysis}

All effective tags were clustered by Uparse software (V7.0.1001) [20]. The sequences with $\geq 97 \%$ similarity 
Table 2. The soil chemical properties of the test plots after being treated with different fertilization treatments.

\begin{tabular}{|c|c|c|c|c|c|}
\hline Parameters & $\mathrm{CK}$ & $\mathrm{F}_{\mathrm{CF}}$ & $\mathrm{F}_{\mathrm{OF}}$ & $\mathrm{F}_{\mathrm{OC}}$ & $\mathrm{F}_{\mathrm{OC} / 4}$ \\
\hline Organic matter $(\mathrm{g} / \mathrm{kg})$ & $7.27 \pm 0.22^{\mathrm{c}}$ & $7.02 \pm 0.02^{\mathrm{c}}$ & $8.85 \pm 0.09^{\mathrm{a}}$ & $8.43 \pm 0.10^{\mathrm{ab}}$ & $8.31 \pm 0.10^{\mathrm{b}}$ \\
\hline Available N $(\mathrm{mg} / \mathrm{kg})$ & $25.59 \pm 0.13^{\mathrm{d}}$ & $28.00 \pm 0.53^{\mathrm{b}}$ & $32.02 \pm 0.17^{\mathrm{a}}$ & $26.92 \pm 0.17^{\mathrm{c}}$ & $24.90 \pm 0.12^{\mathrm{e}}$ \\
\hline Available P $(\mathrm{mg} / \mathrm{kg})$ & $6.62 \pm 0.11^{\mathrm{e}}$ & $11.15 \pm 0.21^{\mathrm{a}}$ & $9.47 \pm 0.12^{\mathrm{d}}$ & $10.67 \pm 0.16^{\mathrm{b}}$ & $10.06 \pm 0.13^{\mathrm{bc}}$ \\
\hline Available K $(\mathrm{mg} / \mathrm{kg})$ & $217.20 \pm 0.58^{\mathrm{e}}$ & $248.60 \pm 0.67^{\mathrm{c}}$ & $284.80 \pm 1.36^{\mathrm{a}}$ & $263.80 \pm 2.70^{\mathrm{b}}$ & $224.40 \pm 1.80^{\mathrm{d}}$ \\
\hline Total N $(\mathrm{g} / \mathrm{kg})$ & $0.46 \pm 0.00^{\mathrm{d}}$ & $0.92 \pm 0.00^{\mathrm{c}}$ & $1.10 \pm 0.01^{\mathrm{a}}$ & $1.07 \pm 0.01^{\mathrm{b}}$ & $0.91 \pm 0.01^{\mathrm{c}}$ \\
\hline Total P $(\mathrm{g} / \mathrm{kg})$ & $0.28 \pm 0.02$ & $0.28 \pm 0.01$ & $0.29 \pm 0.02$ & $0.28 \pm 0.02$ & $0.30 \pm 0.01$ \\
\hline
\end{tabular}

Data was expressed as mean \pm SD. All differences were analyzed by one-way ANOVA followed by multiple comparison with Tukey test. Differences are noted by different low cases. $\mathrm{F}_{\mathrm{CF}}$, treated with $100 \%$ chemical fertilizer. $\mathrm{F}_{\mathrm{OF}}$, treated with $100 \%$ organic fertilizer. $\mathrm{F}_{\mathrm{OC}}$, treated with $50 \%$ organic fertilizer $+50 \%$ chemical fertilizer. $\mathrm{F}_{\mathrm{OC} / 4}$, treated with $25 \%$ organic fertilizer $+25 \%$ chemical fertilizer $+50 \%$ soil conditioner.

were assigned to the same operational taxonomic units (OTUs). The representative sequences for OTUs were selected for annotation of taxonomic information using SILVA database (http://www.arb-silva.de). According to the results of OTU taxonomy, the abundance distribution and composition of each sample at five classification levels (phylum, class, order, family and genus) were obtained using QIIME software. The alpha diversity and beta diversity analyses were performed based on OTUs. Alpha diversity indices, including chaol, good-coverage, observed-species, PD_whole tree, and Shannon, were calculated using QIIME (V1.8, http://qiime.org/scripts/alpha_rarefaction. html). Beta diversity on unweighted unifrac was also calculated by the QIIME software. Principal coordinate analysis (PCoA) was performed to visualize principal coordinates from complex multidimensional data. According to the composition and sequence distribution of each sample at each taxonomic level, the abundance differences of each taxon between two or more samples (groups) could be compared one by one. In the present study, the difference of abundance between groups at each taxonomic level was analyzed using Wilcoxon test. In addition, LDA Effect Size (LEfSe) analysis was conducted to search biomarkers with statistical differences between groups using LEfSe software with LDA Score of 3.

\section{Statistical Analysis}

GraphPad Prism 6 software was used for data statistical analysis. Data were expressed as the mean \pm SD and analyzed by one-way ANOVA followed by multiple comparison with Tukey test. A value of $P<0.05$ was considered significant and $P<0.01$ was considered highly significant.

\section{Results}

\section{Effect of Different Fertilization Treatments on Soil Chemical Properties}

As shown in Table 2, organic matter content was significantly increased after treated with organic or combined fertilizers compared with CK group $(p<0.05)$. Full use of chemical fertilizers can significantly increase the content of soil available P (by about $40.63 \%$ ). Full use of organic fertilizers can significantly increase the content of soil available $\mathrm{N}$ and $\mathrm{K}$ by about $25.13 \%$ and

Table 3. The wine grape berries qualities after being treated with different fertilization treatments

\begin{tabular}{|c|c|c|c|c|c|}
\hline Parameters & CK & $\mathrm{F}_{C F}$ & $\mathrm{~F}_{O F}$ & $\mathrm{~F}_{O C}$ & $\mathrm{~F}_{O C / 4}$ \\
\hline Tannin (mg/g) & $13.81 \pm 0.22^{\mathrm{e}}$ & $18.46 \pm 0.13^{\mathrm{b}}$ & $15.90 \pm 0.20^{\mathrm{d}}$ & $16.81 \pm 0.17^{\mathrm{c}}$ & $20.95 \pm 0.19^{\mathrm{a}}$ \\
\hline Anthocyanin (mg/g) & $5.71 \pm 0.29^{\mathrm{e}}$ & $6.26 \pm 0.19^{\mathrm{d}}$ & $8.17 \pm 0.01^{\mathrm{b}}$ & $6.69 \pm 0.11^{\mathrm{c}}$ & $8.70 \pm 0.01^{\mathrm{a}}$ \\
\hline Total phenols (mg/g) & $16.02 \pm 0.21^{\mathrm{e}}$ & $17.95 \pm 0.29^{\mathrm{d}}$ & $20.19 \pm 0.18^{\mathrm{a}}$ & $19.57 \pm 0.10^{\mathrm{c}}$ & $20.00 \pm 0.29^{\mathrm{ab}}$ \\
\hline Soluble solid (\%) & $25.56 \pm 0.14^{\mathrm{c}}$ & $24.68 \pm 0.25^{\mathrm{d}}$ & $25.90 \pm 0.10^{\mathrm{ab}}$ & $24.68 \pm 0.12^{\mathrm{d}}$ & $26.54 \pm 0.19^{\mathrm{a}}$ \\
\hline Titratable acid (\%) & $0.62 \pm 0.00^{\mathrm{cd}}$ & $0.75 \pm 0.03^{\mathrm{b}}$ & $0.69 \pm 0.02^{\mathrm{c}}$ & $0.68 \pm 0.00^{\mathrm{c}}$ & $0.76 \pm 0.02^{\mathrm{a}}$ \\
\hline
\end{tabular}

Data was expressed as mean $\pm \mathrm{SD}$. All differences were analyzed by one-way ANOVA followed by multiple comparison with Tukey test. Differences are noted by different lowcases. CK, control group without fertilization. $\mathrm{F}_{\mathrm{CF}}$, treated with $100 \%$ chemical fertilizer. $\mathrm{F}_{\mathrm{OF}}$, treated with $100 \%$ organic fertilizer. $\mathrm{F}_{\mathrm{OC}}$, treated with $50 \%$ organic fertilizer $+50 \%$ chemical fertilizer. $\mathrm{F}_{\mathrm{OC} / 4}$, treated with $25 \%$ organic fertilizer $+25 \%$ chemical fertilizer $+50 \%$ soil conditioner. 
$31.12 \%$, respectively. Additionally, $\mathrm{F}_{\mathrm{OC}}$ group increased the NPK content, but did not reach the peak value, which is relatively balanced. $\mathrm{F}_{\mathrm{OC} / 4}$ showed a negative effect on available N. Meanwhile, available $\mathrm{P}$ and $\mathrm{K}$ contents as well as total $\mathrm{N}$ content were obviously increased by all fertilization treatments compared with untreated soil $(p<0.05$, Table 2). However, in comparison with untreated soil, no significant differences were found in the content of total $\mathrm{P}$ by all fertilization treatments (Table 2). These results showed that the combined treatments of organic fertilizer, chemical fertilizer, and soil conditioner had wild impact on soil chemical properties, followed by combined chemical-organic fertilizers.

\section{Effect of Different Fertilization Treatments on Wine Grape Berries Qualities}

Compared with untreated soil (CK), tannin, anthocyanin, total phenols and titratable acid contents in grape was increased by all fertilization treatments. Interestingly, the use of soil conditioner can significantly improve all the indicators of grape quality, and most of the indicators reached the peak after the soil conditioner treatment $(p<0.05$, Table 3$)$. Organic fertilization treatment had little impacts on the content of titratable acid, tannin and soluble solid, but significantly increased the total phenols by $26.03 \%$. In general, the incorporation of soil conditioner is very significant for improving the value of grape quality indicators.

\section{Differences in Bacterial Diversity Among Fertilizations}

A total of $1,003,491$ valid sequences were generated from 25 samples in five groups by Illumina sequencing, and then clustered into 4908 OTUs at the $97 \%$ similarity level. The alpha diversity indexes for all groups are shown in Fig. 1, which suggested the high community richness, high community diversity, and high phylogenetic diversity. The Chaol and $\mathrm{PD}$ whole tree indexes in CK was significantly higher than that in Foc, indicating that the application of $50 \%$ chemical fertilizer and $50 \%$ organic fertilizer significantly reduced the bacteria richness. Rarefaction curve of each sample did not tend to flatten (Fig. 2a), a)

Chao1

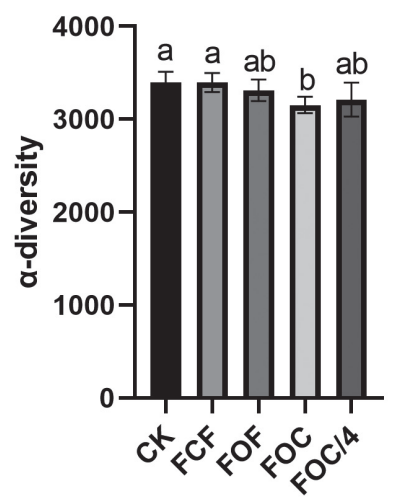

Groups

d)

PD whole tree

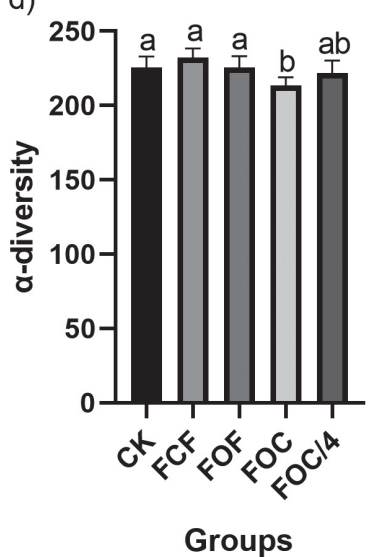

b) Goods coverage

c) Observed species

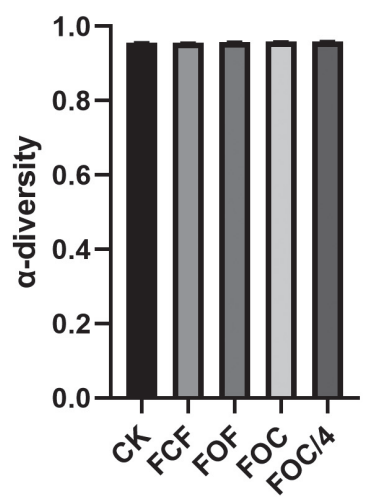

Groups

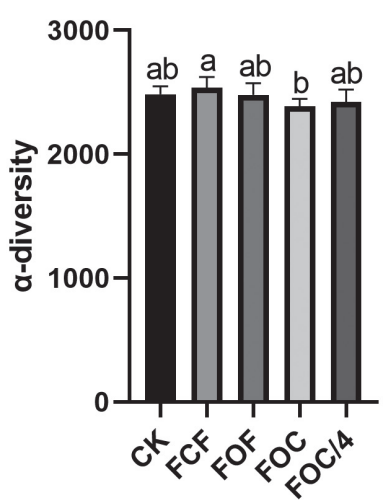

Groups

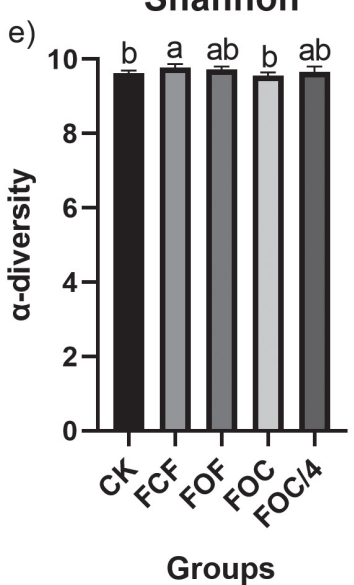

Fig. 1. Alpha diversity indexes.

a) to e) shows the value of Chao1, Goods coverage, Observed species, PD whole tree and Shannon, respectively. Different letters indicate $p<0.05 . \mathrm{F}_{\mathrm{CF}}$, treated with $100 \%$ chemical fertilizer. $\mathrm{F}_{\mathrm{OF}}$, treated with $100 \%$ organic fertilizer. $\mathrm{F}_{\mathrm{OC}}$, treated with $50 \%$ organic fertilizer + $50 \%$ chemical fertilizer. $\mathrm{F}_{\mathrm{OC} / 4}$, treated with $25 \%$ organic fertilizer $+25 \%$ chemical fertilizer $+50 \%$ soil conditioner. 
suggesting that increasing sequencing depths could help to discover new OTUs. PCoA analysis showed that the samples in the same group tended to cluster together, and were separated obviously from that in the other group (Fig. 2B). Additionally, according to the results of OTUs annotation, the top 20 maximum a)

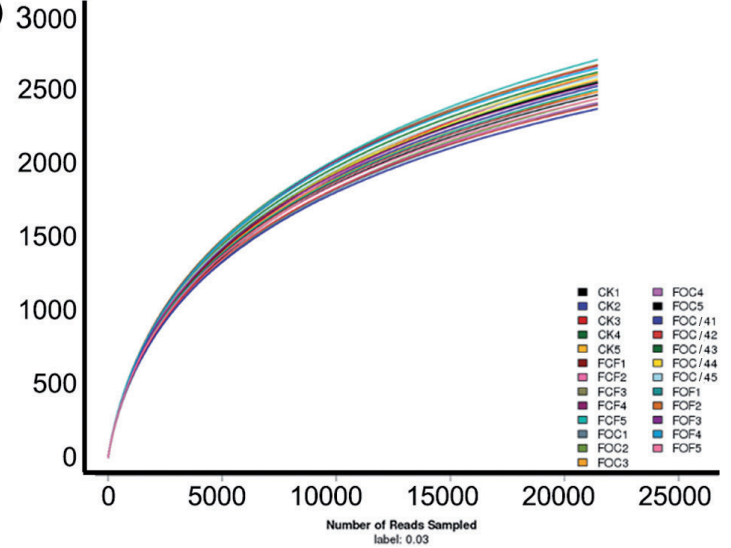

b)

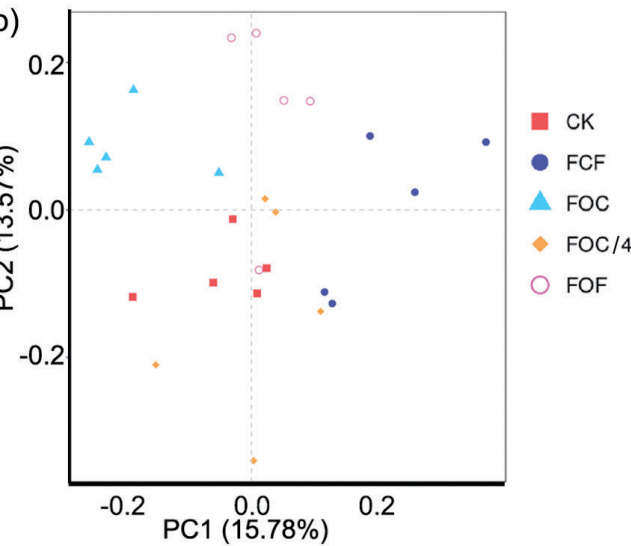

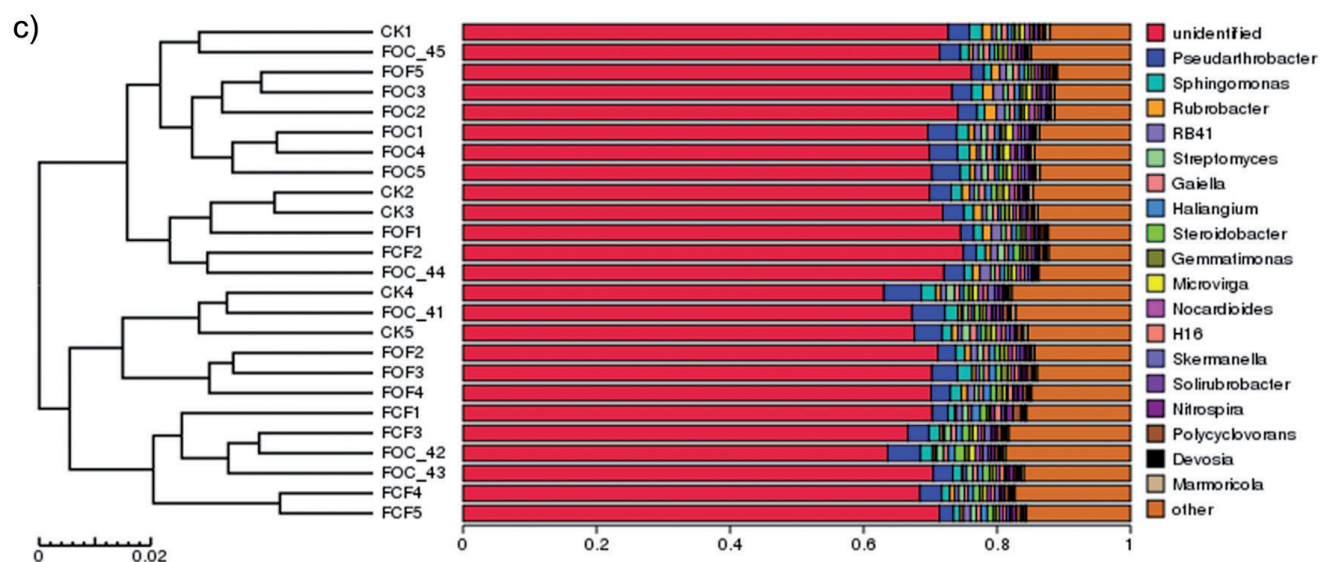

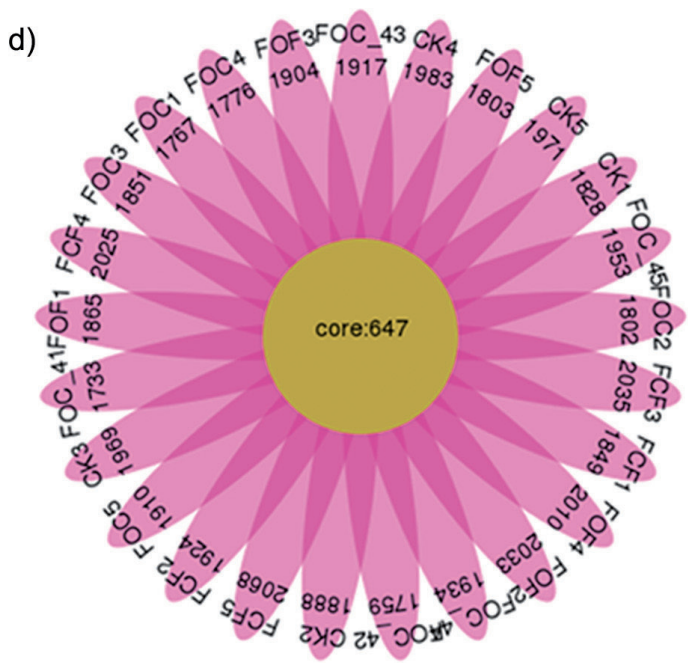

Fig. 2. Summary and statistics of the operational taxonomic units (OTUs). a) Rarefaction curve for each group. The $x$-axis is the number of sequencing bars randomly selected from a group, and the $y$ - axis is the number of OTUs constructed based on the number of sequencing bars. b) The results of PCoA. The x-axis represents one principal component, the y-axis represents another principal component, and the percentage represents the contribution of the principal component to the sample difference. Each node represents a sample, and the samples from the same group are represented by the same color. c) The UPGMA clustering tree in genus level. d) The flower diagram of OTUs in the five groups. Each petal represents one sample. The number of middle core represents the number of OTUs common to all samples, and the number on the petals represents the number of OTUs unique to the sample. $\mathrm{F}_{\mathrm{CF}}$, treated with $100 \%$ chemical fertilizer. $\mathrm{F}_{\mathrm{OF}}$, treated with $100 \%$ organic fertilizer. $\mathrm{F}_{\mathrm{OC}}$, treated with $50 \%$ organic fertilizer $+50 \%$ chemical fertilizer. $\mathrm{F}_{\mathrm{OC} / 4}$, treated with $25 \%$ organic fertilizer $+25 \%$ chemical fertilizer $+50 \%$ soil conditioner. 
abundance of species in each group in five taxonomic levels (phylum, class, order, family, and genus) were selected to generate the column accumulation graph of species relative abundance. The relative abundance of species in genera level is shown by the UPGMA clustering tree (Fig. 2c). The flower diagram of OTUs distribution in 25 samples of the five groups is shown in Fig. 2d), which consisted of 647 common OTUs in 25 samples. The results revealed that Pseudarthrobacter, Sphingomonas, Rubrobacter, RB41, Streptomyces were the top five dominant genera among the five groups.

\section{Differential Analysis of Taxonomic Composition Among the Five Groups}

The species with relative abundance of more than $1 \%$ in phylum level included Proteobacteria, Chloroflexi, Gemmatimonadetes, Actinobacteria, and Acidobacteria (Fig. 3a). Wilcoxon test showed that compared with the $\mathrm{CK}$ group, chemical fertilizer $\left(\mathrm{F}_{\mathrm{CF}}\right)$ inhibited the relative abundances of Gemmatimonadetes and Actinobacteria $(\mathrm{p}<0.05$, Fig. 3b). No significant differences were observed in other bacteria. Seven genera with relative abundance of more than $1 \%$ were identified, including Rubrobacter, Haliangium, Pseudarthrobacter, RB41, Steroidobacter, Sphingomonas, and Streptomyces (Fig. 3c). Wilcoxon test showed that compared with the CK group, chemical fertilizer $\left(\mathrm{F}_{\mathrm{CF}}\right)$ inhibited the relative abundance of Rubrobacter and increased the relative abundance of Steroidobacter; while the addition of organic fertilizers $\left(\mathrm{F}_{\mathrm{OC}}\right)$ recovered the relative abundances of Rubrobacter and Steroidobacter $(\mathrm{p}<0.05$, Fig. 3d). In addition, the combination of chemical and organic fertilizers reduced the relative abundances of Steroidobacter and Haliangium in comparison with single organic fertilizers ( $\mathrm{p}<0.05$, Fig. $3 \mathrm{e})$.

\section{Dominant Bacteria Among the Five Groups}

LEfSe analysis was used to search dominant bacteria among groups (Fig. 4), and the results showed that Gemmatimonadetes, Longimicrobia, and Longimicrobiaceae were significant species in the $\mathrm{F}_{\mathrm{OF}}$ group; Rhizobiales and Sphingobacteriales, and Hyphomicrobiaceae were significantly differential species in the $\mathrm{F}_{\mathrm{OC} 4}$ group; Actinobacteria, Thermoleophilia, and Solirubrobacterales were a)

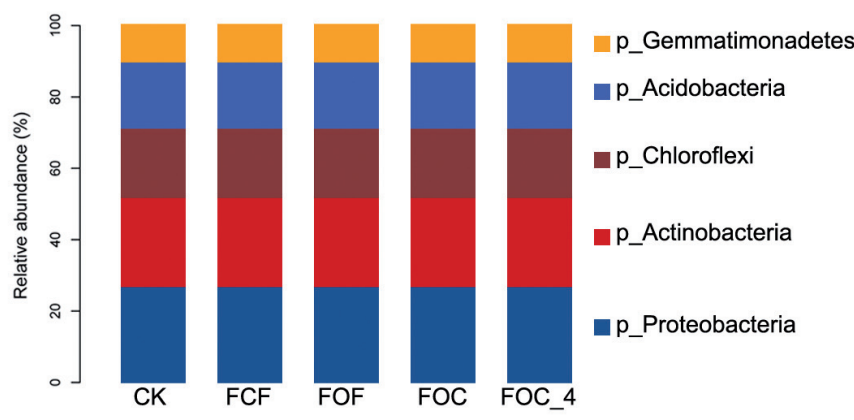

c)

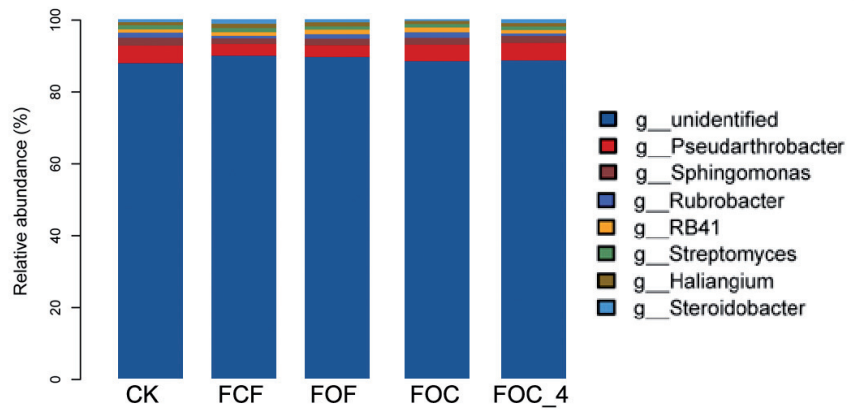

b)

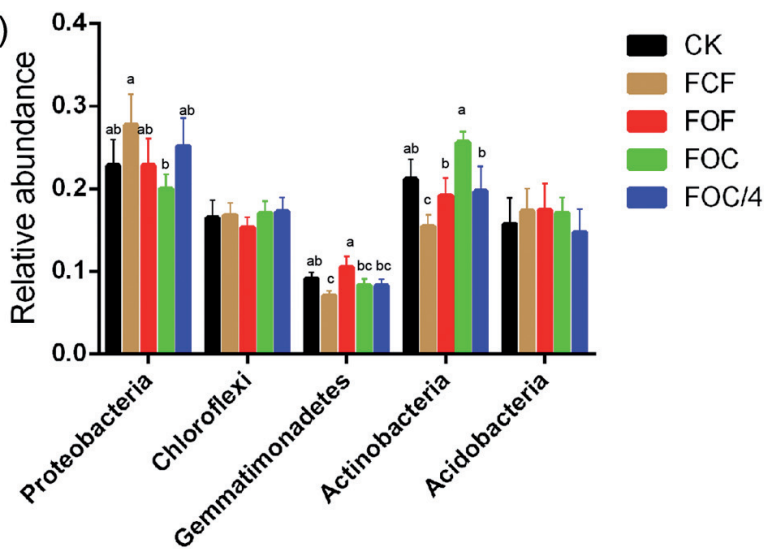

d)

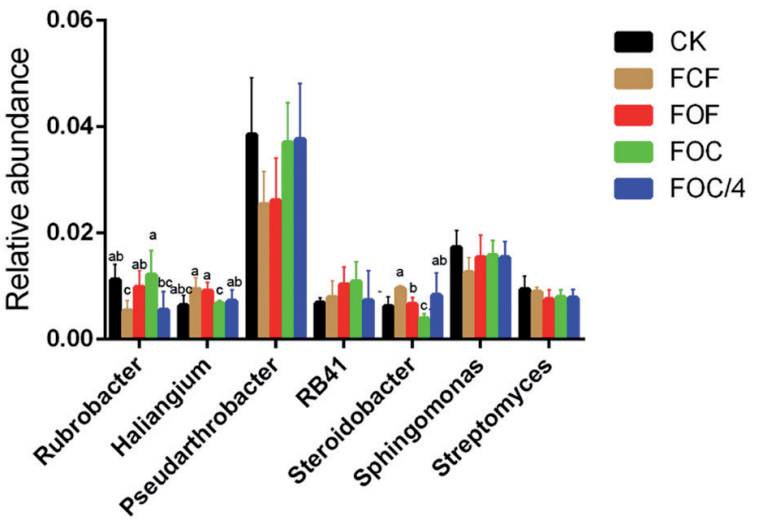

Fig. 3. Relative abundance of the taxonomic composition in phylum and genus level. a) the taxonomic composition with the relative abundance of more than $1 \%$ in phylum level by distribution histogram. b) the statistical analysis for the relative abundance of the dominant bacterial phyla by Wilcoxon test. c)the taxonomic composition with the relative abundance of more than $1 \%$ in genus level by distribution histogram. d) the statistical analysis for the relative abundance of the dominant bacterial genera by Wilcoxon test. Differences are noted by different lowcases above the column. $\mathrm{CK}$, control group without fertilization. $\mathrm{F}_{\mathrm{CF}}$, treated with $100 \%$ chemical fertilizer. $\mathrm{F}_{\mathrm{OF}}$, treated with $100 \%$ organic fertilizer. $\mathrm{F}_{\mathrm{OC}}$, treated with $50 \%$ organic fertilizer $+50 \%$ chemical fertilizer. $\mathrm{F}_{\mathrm{OC} / 4}$, treated with $25 \%$ organic fertilizer $+25 \%$ chemical fertilizer $+50 \%$ soil conditioner. 
a)

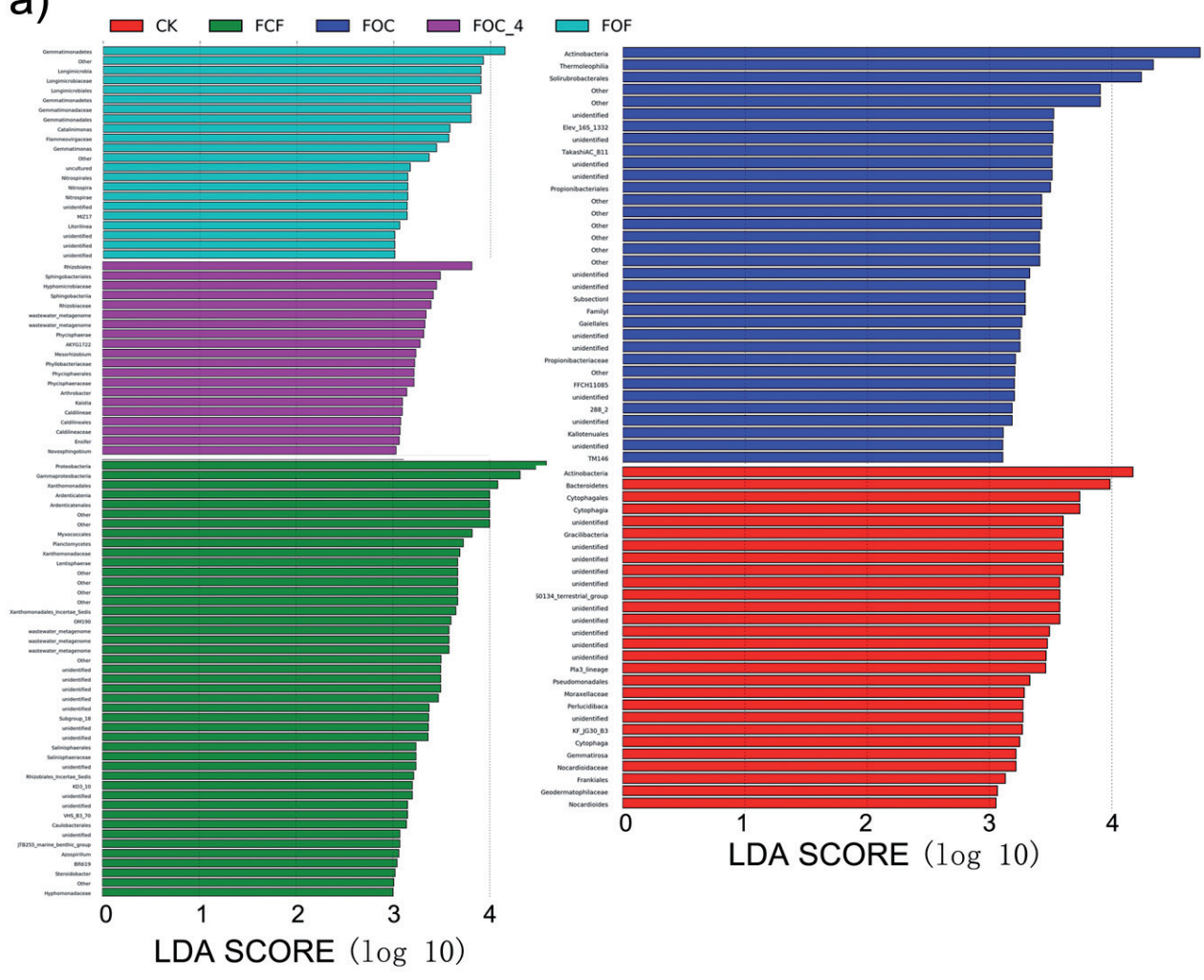

b) Cladogram
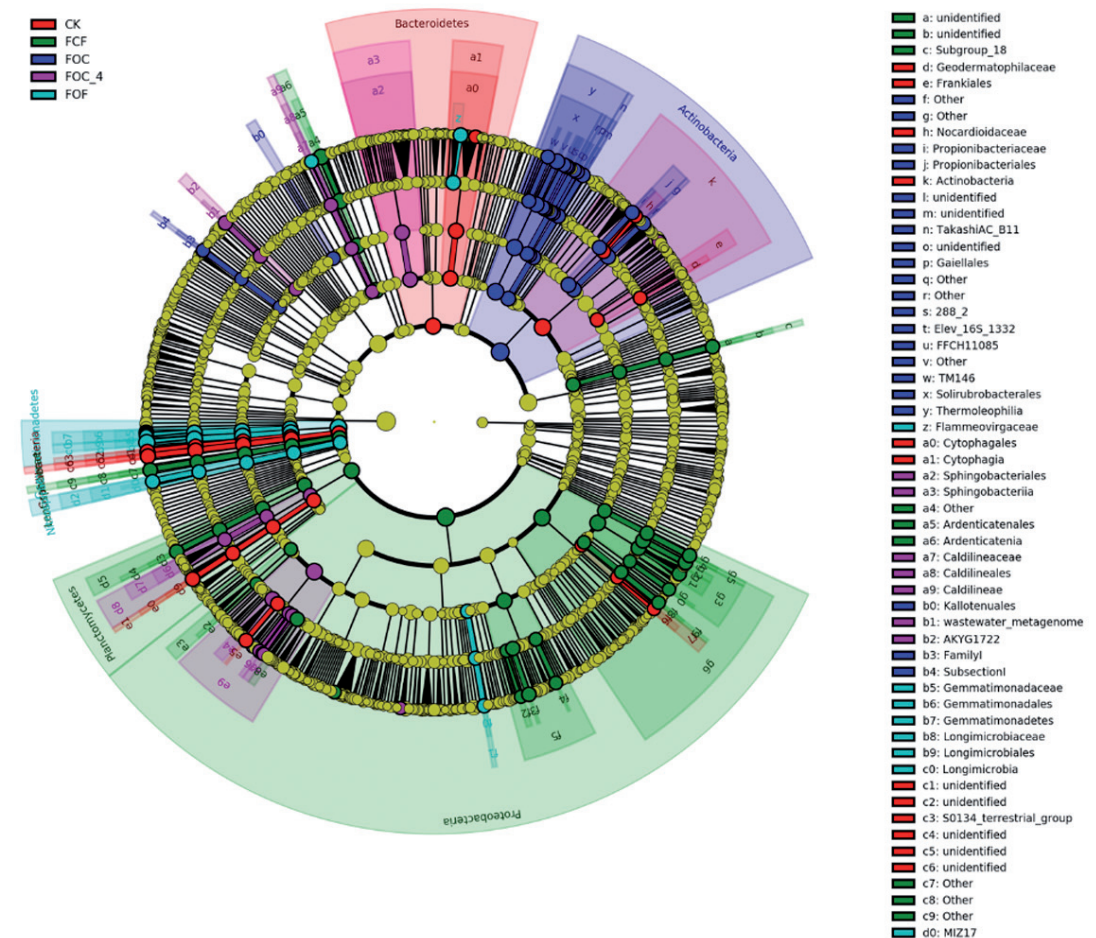

Fig. 4. LDA value distribution histogram a) and evolutionary branching diagram b). LDA value distribution histogram shows the species whose LDA score is greater than the set value (the default setting is 3 ). In an evolutionary bifurcation diagram, a circle radiates from inside to outside represents the taxonomy level from phylum to the genus (or species). Each small circle at different taxonomy levels represents a taxonomy under that level, and the size of the small circle is proportional to the relative abundance. Coloring principle: yellow represents no significant difference. The significantly differential species is colored according to the group. $\mathrm{F}_{\mathrm{CF}}$, treated with $100 \%$ chemical fertilizer. $\mathrm{F}_{\mathrm{OF}}$, treated with $100 \%$ organic fertilizer. $\mathrm{F}_{\mathrm{OC}}$, treated with $50 \%$ organic fertilizer $+50 \%$ chemical fertilizer. $\mathrm{F}_{\mathrm{OC} / 4}$, treated with $25 \%$ organic fertilizer $+25 \%$ chemical fertilizer $+50 \%$ soil conditioner. 
significantly differential species in the $\mathrm{F}_{\mathrm{OC}}$ group; Proteobacteria, Gammaproteobacteria, and Xanthomonadales were significantly differential species in the $\mathrm{F}_{\mathrm{CF}}$ group. Actinobacteria, Bacteroidetes, and Cytophagales were significantly differential species in the CK group.

\section{Discussion}

High soil fertility can improve the quality of wine grape berry, which contributes to the better beneficial effects of wine on human health [4]. The grape quality was detected in this study, and combined treatments of organic fertilizer, chemical fertilizer, and soil conditioner increased the contents of tannin, total phenols, soluble solids, titratable acid and anthocyanin. Single organic fertilizers showed the increased contents of tannin, total phenols, soluble solid and anthocyanin, as well as little impacts, were found in the content of titratable acid. Total phenolic compounds are the primary element responsible for the flavor and aroma of wine, and anthocyanin also belongs to flavonoids of phenolic compounds [21]. It has been evidenced that phenolic compounds could exert antioxidant and antimicrobial properties [22]. In addition, tannin is also an indicator responsible for wine aroma by inducing the production of free thiols in wine [23]. These results suggested that combined organic fertilizer, chemical fertilizer, and soil conditioner could improve the grape quality, followed by single organic fertilizer.

Meanwhile, the present study showed that chemical fertilizer increased the available $\mathrm{P}$ and $\mathrm{K}$ contents as well as total $\mathrm{N}$ content, but had no influence on the organic matter content. This result was consistent with a previous study that reported the undesirable effects of the long-term application of chemical fertilizer in crop quality [24]. Certainly, this study also revealed that the addition of organic fertilizers increased the organic matter content, as well as available $\mathrm{P}$ and $\mathrm{K}$ contents and total $\mathrm{N}$ content, suggested higher soil fertility of organic fertilizers than chemical fertilizers. Moreover, we found enhanced soil fertility induced by the addition of soil conditioner. Similarly, a previous study has also shown that soil conditioners can recover soil fertility in degraded vineyards, as well as enhance the grape quality [25].

Microbial growth and distribution is affected by the chemical properties of soil [26], and the interaction of soil microorganism and plant growth is complex. The present study compared the soil bacterial community diversity under different fertilization treatments, and the bacteria in phylum and genus levels were mainly focused. Soil bacteria are an essential part of soil microbes, and most of the dominant soil bacteria are basically similar, including about 10 bacterial taxa [27]. Our results showed that Proteobacteria, Chloroflexi, Gemmatimonadetes, Actinobacteria, and Acidobacteria were dominant soil bacterial taxa at the phylum level, which was consistent with a previous study [28]. In this study, Gemmatimonadetes and Actinobacteria were significantly differential species among different fertilization treatments. Compared with the untreated group, the relative abundances of Gemmatimonadetes and Actinobacteria were significantly inhibited by chemical fertilizer, while were recovered by organic fertilizers. In addition, compared with chemical fertilizer, the combined fertilizers also could enhance the relative abundances of Gemmatimonadetes and Actinobacteria. Considering the above results that organic fertilizer and soil conditioner could improve grape quality, we speculated that Gemmatimonadetes and Actinobacteria might be important functional soil bacteria for the quality of wine grape, and similar results were reported by Zhao et al. [29].

At the genus level, Rubrobacter, Haliangium, Pseudarthrobacter, RB41, Steroidobacter, Sphingomonas, and Streptomyces were identified as predominant genera in this study. Particularly, Rubrobacter and Steroidobacter were significantly differential species among different fertilization treatments. Compared with the untreated group, chemical fertilizer inhibited the relative abundance of Rubrobacter and increased the relative abundance of Steroidobacter; while organic fertilizers had the contrary effects on the relative abundances of Rubrobacter and Steroidobacter in comparison with chemical fertilizer. In addition, the addition of soil conditioner decreased the relative abundance of Rubrobacter and increased the relative abundance of Steroidobacter compared with the combination of chemical and organic fertilizers. Rubrobacter, belonging to Actinobacteria, is a photosynthetic and radiation-resistant bacterium widely distributed in soil, paddy fields and rivers [30]. Increased abundance of Rubrobacter is beneficial to contribute to enhance soil fertility and promote plant growth [30, 31]. Steroidobacter belonging to Proteobacteria is involved in anoxic metabolism of steroids [32]. These results suggested that an increased abundance of Rubrobacter and reduced abundance of Steroidobacter induced by organic fertilizers might play an important role in the improvement of the grape quality.

\section{Conclusions}

In conclusion, organic fertilizers and soil conditioners could enhance soil fertility and improve wine grape berry quality. Furthermore, the favorable effects of the application of organic fertilizers and soil conditioners on soil fertility and grape quality might be associated with the abundance changes of soil bacteria, including Gemmatimonadetes and Actinobacteria phyla as well as Rubrobacter and Steroidobacter genera. However, more samples are necessary to investigate and determine the fertilization tactics via understanding the interaction and impact of community diversity of these bacteria on wine grape quality. 


\section{Abbreviations}

NGS: next-generation sequencing; $\mathbf{N}$ : Nitrogen; P: phosphorus; K: potassium; CK: no fertilization); $\mathbf{F}_{\mathrm{CF}}: 100 \%$ chemical fertilizer; the composition and the application rate: pure $\mathrm{N} 363 \mathrm{~kg} / \mathrm{hm}^{2}, \mathrm{P}_{2} \mathrm{O}_{5} 177 \mathrm{~kg} / \mathrm{hm}^{2}$, and $\mathrm{K}_{2} \mathrm{O} 330 \mathrm{~kg} / \mathrm{hm}^{2} ; \mathbf{F}_{\mathrm{OF}}: 100 \%$ organic fertilizer; the application rate: $9 \mathrm{t} / \mathrm{hm}^{2} ; \mathrm{F}_{\mathrm{OC}}: 50 \%$ organic fertilizer + $50 \%$ chemical fertilizer; $\mathbf{F}_{\mathrm{OC} / 4}: 25 \%$ organic fertilizer $+25 \%$ chemical fertilizer $+50 \%$ soil conditioner; the application rate of soil conditioner: $3 \mathrm{t} / \mathrm{hm}^{2}$; OUTs: operational taxonomic units; PCoA: Principal coordinate analysis; LEfSe: LDA Effect Size

\section{Acknowledgements}

This study was supported by the national science and technology reform and development project (106001000000150012), The key research and development program of Ningxia (2016BZ06 and 2018BBF02021), Ningxia agricultural science and technology independent innovation project (YES-201606 and 2017BN05).

\section{Conflict of Interest}

The authors declare that there is no conflict of interests regarding the publication of this paper.

\section{References}

1. MENCARELLI F., BELLINCONTRO A. Recent advances in postharvest technology of the wine grape to improve the wine aroma. Journal of the Science of Food and Agriculture. 2018.

2. GIOVINAZZO G., CARLUCCIO M.A., GRIECO F. Wine Polyphenols and Health. Bioactive Molecules in Food. 1135, 2019.

3. ETIÉVANT P.X. Wine. Volatile compounds in foods and beverages: Routledge; 483, 2017

4. RETALLACK G.J., BURNS S.F. The effects of soil on the taste of wine. GSA Today. 26 (5), 2016.

5. MARTÍNEZ M.J.Q., MORÁN M.Á.O., GARCÍA M.S., MEDINA J.E., RELUY F.V., COQUE J.J.R., JIMENO J.E.G. Effects of liming on soil properties, leaf tissue cation composition and grape yield in a moderately acid vineyard soil. Influence on must and wine quality. OENO ONE: Journal international des sciences de la vigne et du vin $=$ International journal of vine and wine sciences. $\mathbf{5 1}$ (4), 343, 2017.

6. HAVLIN J.L., TISDALE S.L., NELSON W.L., BEATON J.D. Soil fertility and fertilizers: Pearson Education India; 2016.

7. SINGH B., RYAN J. Managing fertilizers to enhance soil health. International Fertilizer Industry Association, Paris, France. 1, 2015.

8. FAGERIA N.K. The use of nutrients in crop plants: CRC press; 2016.
9. MONDAL T., DATTA J.K., MONDAL N.K. Chemical fertilizer in conjunction with biofertilizer and vermicompost induced changes in morpho-physiological and bio-chemical traits of mustard crop. Journal of the Saudi Society of Agricultural Sciences. 16 (2), 135, 2017.

10. MALTAS A., KEBLI H., OBERHOLZER H.R., WEISSKOPF P., SINAJ S. The effects of organic and mineral fertilizers on carbon sequestration, soil properties, and crop yields from a long-term field experiment under a Swiss conventional farming system. Land degradation \& development. 29 (4), 926, 2018.

11. NANNIPIERI P., ASCHER J., CECCHERINI M., LANDI L., PIETRAMELlARA G., RENELlA G. Microbial diversity and soil functions. European journal of soil science. 68 (1), 12, 2017.

12. BRUSSAARD L., DE RUITER P.C., BROWN G.G. Soil biodiversity for agricultural sustainability. Agriculture, ecosystems \& environment. 121 (3), 233, 2007.

13. TAUTGES N.E., SULLIVAN T.S., REARDON C.L., BURKE I.C. Soil microbial diversity and activity linked to crop yield and quality in a dryland organic wheat production system. Applied Soil Ecology. 108 (258), 2016.

14. LI F., CHEN L., ZHANG J., YIN J., HUANG S. Bacterial Community Structure after Long-term Organic and Inorganic Fertilization Reveals Important Associations between Soil Nutrients and Specific Taxa Involved in Nutrient Transformations. Frontiers in Microbiology. 8 (187), 2017.

15. HE Y., LU L., PENG C., et al. High-yield grass Pennisetum sinese Roxb plantation and organic manure alter bacterial and fungal communities structure in an ecological agriculture farm. AMB Express. 10 (1), 86, 2020.

16. BAO S. Soil agrochemical analysis. Chinese.) China Agricultural Press, Beijing. 30, 2000.

17. LI H., SUN Q., ZHAO S.-J. The experiment principle and technique for plant physiology and biochemistry: Beijing: Higher Education Press; 164, 2000.

18. FERNÁNDEZ S.L., VĚTROVSKÝ T., BALDRIAN P. The concept of operational taxonomic units revisited: genomes of bacteria that are regarded as closely related are often highly dissimilar. Folia microbiologica. 64 (1), 19, 2019.

19. JIANG T., ZHAN X., XU Y., ZHOU L., ZONG L. Roles of calcium in stress-tolerance of plants and its ecological significance. Ying yong sheng tai xue bao $=$ The journal of applied ecology. 16 (5), 971, 2005.

20. EDGAR R.C. UPARSE: highly accurate OTU sequences from microbial amplicon reads. Nature methods. 10 (10), 996, 2013.

21. URCAN D.E., LUNG M.-L., GIACOSA S., TORCHIO F., FERRANDINO A., VINCENZI S., RÍO SEGADE S., POP N., ROLLE L. Phenolic substances, flavor compounds, and textural properties of three native Romanian wine grape varieties. International journal of food properties. 19 (1), 76, 2016.

22. SILVA V., GREJAS G., FALCO V., SANTOS T.P., TORRES C., OLIVEIRA A.M., PEREIRA J.E., AMARAL J.S., POETA P. Chemical composition, antioxidant and antimicrobial activity of phenolic compounds extracted from wine industry by-products. Food control. 92 (516), 2018.

23. LARCHER R., TONIDANDEL L., VILLEGAS T.R., NARDIN T., FEDRIZZI B., NICOLINI G. Prefermentation addition of grape tannin increases the varietal thiols content in wine. Food chemistry. 166 (56), 2015.

24. MAO X., XU X., LU K.,GIELEN G., LUO J., HE L., DONNISON A., XU Z., XU J., YANG W. Effect of 17 
years of organic and inorganic fertilizer applications on soil phosphorus dynamics in a rice-wheat rotation cropping system in eastern China. Journal of soils and sediments. 15 (9), 1889, 2015.

25. MONDINI C., FORNASIER F., SINICCO T., SIVILOTTI P., GAIOTTI F., MOSETTI D. Organic amendment effectively recovers soil functionality in degraded vineyards. European Journal of Agronomy. 101 (210, 2018.

26. ZHANG Q., ZHOU W., LIANG G., SUN J., WANG X., HE P. Distribution of soil nutrients, extracellular enzyme activities and microbial communities across particle-size fractions in a long-term fertilizer experiment. Applied Soil Ecology. 94 (59, 2015.

27. PHILIPPOT L., ANDERSSON S.G., BATTIN T.J., PROSSER J.I., SCHIMEL J.P., WHITMAN W.B., HALLIN S. The ecological coherence of high bacterial taxonomic ranks. Nature Reviews Microbiology. 8 (7), $523,2010$.
28. SUN M., XIAO T., NING Z., XIAO E., SUN W. Microbial community analysis in rice paddy soils irrigated by acid mine drainage contaminated water. Applied microbiology and biotechnology. 99 (6), 2911, 2015.

29. ZHAO P., XIA W., WANG J., ZHANG X., ZHUANG Y., LU Q., CHEN S. Bacterial Diversity of Grapevine Rhizosphere Soil Revealed by High-Throughput Sequence Analysis from Different Vineyards in China. Journal of Biobased Materials and Bioenergy. 12 (2), 194, 2018.

30. GUPTA R.S., KHADKA B. Evidence for the presence of key chlorophyll-biosynthesis-related proteins in the genus Rubrobacter (Phylum Actinobacteria) and its implications for the evolution and origin of photosynthesis. Photosynthesis research. 127 (2), 201, 2016.

31. CARDONA T. Evolution of Photosynthesis. eLS. 1, 2001.

32. CHIANG Y.-R., FANG J.-Y., ISMAIL W., WANG P.H. Initial steps in anoxic testosterone degradation by Steroidobacter denitrificans. Microbiology. 156 (7), 2253, 2010. 